\title{
Emprego da submucosa de intestino delgado porcina no reparo de lesões do esôfago cervical. Estudo experimental em cães ${ }^{1}$
}

\author{
Zacarias Alves de Souza Filho \\ Sérgio Ossamu Ioshii ${ }^{3}$ \\ Fernando Hintz Greca ${ }^{4}$ \\ Maria de Lourdes Pessole Biondo-Simões ${ }^{5}$ \\ Sérgio Luiz Rocha ${ }^{6}$ \\ João Ricardo Duda ${ }^{7}$ \\ Hélio Rubens de Oliveira Filho ${ }^{7}$
}

\begin{abstract}
Souza Filho ZA, Ioshii SO, Greca FH, Biondo-Simões MLP, Rocha SL, Duda JR, Oliveira Filho HR. Emprego da submucosa de intestino delgado porcina no reparo de lesões do esôfago cervical: estudo experimental em cães. Acta Cir Bras [serial online] 2003 Maio-Jun;18(3). Disponível em URL: http://www.scielo.br/acb.

RESUMO - Objetivo: Pesquisar a eficácia da submucosa de intestino delgado (SID) porcina como enxerto para reparo de lesões em esôfago cervical de cães. Métodos: Foram operados 10 cães. Ressecou-se parcialmente uma porção da parede anterior do esôfago que foi substituída por um enxerto de SID. Avaliaram-se a resistência tensiométrica, o aspecto macroscópico, a regeneração tecidual e a concentração de colágeno da porção esofágica onde se implantou o enxerto. Resultados: Não houve infecção, fístula ou estenose. Verificou-se ganho semelhante de resistência do esôfago operado em relação ao controle: $31.84 \mathrm{~N}$ contra $28.60 \mathrm{~N}$ em média $(\mathrm{p}=0,593)$. A macroscopia revelou cicatrização completa com pouca retração tecidual. O estudo anátomo-patológico por HE mostrou re-epitelização completa da mucosa, proliferação vascular discreta a moderada e proliferação fibroblástica intensa. Na análise do colágeno pelo Sirus-red obteve-se em média 54.04\% de colágeno tipo I, 16,04\% de colágeno tipo III e 71.58\% de colágeno total. Conclusão: A SID mostrou ser, no cão, um enxerto eficaz no reparo de lesões maiores do esôfago, apresentando-se resistente à infecção e à rejeição. A SID deve ser, portanto, considerada opção importante no tratamento destas lesões.

DESCRITORES - Lesões. Esôfago. Submucosa. Cirurgia experimental.
\end{abstract}

1. Trabalho realizado na Disciplina de Técnica Operatória e Cirurgia Experimental da Pontifícia Universidade Católica do Paraná (PUCPR).

2. Prof. Titular de Clínica Cirúrgica do CCBS-PUCPR e da Disciplina de Técnica Operatória e Cirurgia Experimental da PUCPR e da UFPR.

3. Prof. Adjunto de Anatomia Patológica das Faculdades de Medicina da PUCPR e UFPR.

4. Prof. Titular e Coordenador da Disciplina de Técnica Operatória e Cirurgia Experimental da PUCPR e Prof. Adjunto da Disciplina de Cirurgia Geral da UFPR .

5. Prof ${ }^{\text {a }}$ Titular de Técnica Operatória e Cirurgia Experimental e Coordenadora da Disciplina de Metodologia Científica da PUCPR. Prof. Adjunta e Coordenadora da Disciplina de Técnica Cirúrgica e Cirurgia Experimental da UFPR.

6. Prof. Adjunto da Disciplina de Anatomia Médica da PUCPR e UFPR. Prof. Adjunto da Disciplina de Técnica Operatória e Cirurgia Experimental da PUCPR.

7. Alunos do Curso de Medicina: Iniciação Científica da Disciplina de Técnica Operatória e Cirurgia Experimental da PUCPR. 


\section{Introdução}

O esôfago é a porção do trato digestório que comunica a faringe ao estômago. Divide-se em esôfago cervical, torácico e abdominal ${ }^{1}$. Caracteriza-se por não apresentar serosa ${ }^{2}$. As perfurações traumáticas são responsáveis por considerável fração das lesões esofágicas e normalmente estão associadas a lesões vasculares, neurológicas e de vias aéreas ${ }^{3,4,5,6}$. O reparo de lesões esofágicas com perda significante de tecido está associado a grande morbidade e mortalidade ${ }^{3,4}$. Pequenas lesões detectadas precocemente podem ser tratadas com sutura primária. Podem ser também reforçadas com retalhos de músculos vascularizados, bem como enxertos de pleura parietal, fundo do estômago, aorta porcina descelularizada, entre outros $^{3,4,7,8}$. Ressecção segmentar e anastomose términoterminal primária são condutas de exceção e requerem extensa dissecção e mobilização do esôfago. A tensão na linha de sutura num órgão sem serosa com frequiência propicia a formação de fístulas e estenoses ${ }^{3,4,5,6}$. Em muitas situações o paciente apresenta-se clinicamente instável havendo a necessidade de uma terapêutica rápida e de fácil execução. Em lesões diagnosticadas tardiamente, certo grau de necrose tecidual pode já estar instalado e extenso debridamento pode ser necessário, causando mais perda tecidual ${ }^{3,4}$. O uso de exclusão esofágica predispõe à necessidade de gastrostomia, esofagostomia e/ou alimentação parenteral e está relacionado a elevado coeficiente de mortalidade ${ }^{3,4,9,10,11}$. A submucosa de intestino delgado de suínos (SID) é uma matriz colágena extracelular ${ }^{12}$ que vem sendo utilizada com bons resultados no reparo de tecidos vasculares $^{12}$, do aparelho urinário ${ }^{13,14}$, da parede abdominal ${ }^{15}$ e das cartilagens ${ }^{16}$, entre outros. Segundo diversos autores, a SID apresenta características próprias que proporcionam a ela vantagens em relação aos demais enxertos biológicos. Dentre elas estão a presença de glicosaminoglicanos que conferem bioatividade a diversas citocinas e fatores de crescimento que atuam na revascularização e cicatrização de ferimentos ${ }^{17}$. O fator de crescimento do endotélio (VEGF) induz a formação de estruturas similares a capilares fenestrados na matriz de fibrina, promovendo neovascularização local ${ }^{18}$. O fator de crescimento derivado de plaquetas (PDGF) atua na proliferação fibroblástica ${ }^{19,20}$ e é suplementado pela imediata deposição de fibronectina, responsável primária pelo recrutamento e pela retenção das células do hospedeiro que povoarão o local da ferida $^{21,22}$. Com relação à resposta imune da SID, observou-se que esta é restrita aos linfócitos T-helper 2 , que ativam interleucinas que produzem anticorpos não ligados a complementos e, conseqüentemente, não há uma rejeição típica do tecido implantado ${ }^{23,24}$. A resistência à infecção está provavelmente correlacionada ao rico e rápido desenvolvimento de suprimento sangüíneo ${ }^{25}$. A SID já foi utilizada como enxerto no reparo de lesões esofágicas em cães. Apresentou baixo grau de estenose, epitelização completa, organização das fibras musculares e moderada vascularização ${ }^{26}$. As promissoras características da membrana submucosa, os bons resultados descritos na literatura em relação à sua aplicação, a morbidade das lesões esofágicas e a ausência de um consenso em relação a seu tratamento nos motivou a pesquisar, experimentalmente, a eficácia da SID porcina como enxerto parcial no reparo de lesões com perda de substância do esôfago cervical em cães.

\section{Métodos}

O enxerto de submucosa de intestino delgado de suíno é obtido da seguinte maneira: uma porção do jejuno é removida dentro de 10 minutos após a eutanásia do animal e imediatamente colocada numa solução salina a $0,9 \%$. O segmento inicialmente é invertido e a túnica mucosa é mecanicamente removida; posteriormente é re-invertido e tanto a serosa quanto a túnica muscular são removidas. É então obtido um fino e translúcido tecido composto da submucosa. Irriga-se com solução salina a $0,9 \%$ e conserva-se em solução de sulfato de neomicina $10 \%$.

Dez cães mestiços, com peso entre 10 e $20 \mathrm{Kg}$, foram mantidos no Biotério da PUCPR e o experimento foi realizado no Laboratório de Técnica Operatória e Cirurgia Experimental da PUCPR

Sob anestesia, realizou-se cervicotomia paratraqueal esquerda de $8 \mathrm{~cm}$ Expôs-se o esôfago e de sua parede anterior, ressecou-se uma porção elíptica de aproximadamente $3,5 \mathrm{~cm}$ de comprimento, correspondendo a um terço da circunferência total do órgão (Figura 1). Realizou-se o reparo da lesão com o enxerto composto de dois folhetos de SID de $3 \times 4 \mathrm{~cm}$, que foi fixado à brecha feita no esôfago com sutura contínua entre o enxerto e as camadas mucosa e submucosa do esôfago. Usou-se fio de poliglecaprone 25(Monocryl $\left.{ }^{\circledR}\right) 4.0$ (Figuras 2 e 3). Fez-se a síntese da pele com fio monofilamentar de náilon 3.0 (Mononylon ${ }^{\circledR}$ ), com pontos à Donatti. A lesão foi induzida e corrigida no segmento superior do esôfago cervical. O segmento inferior foi utilizado como controle. 


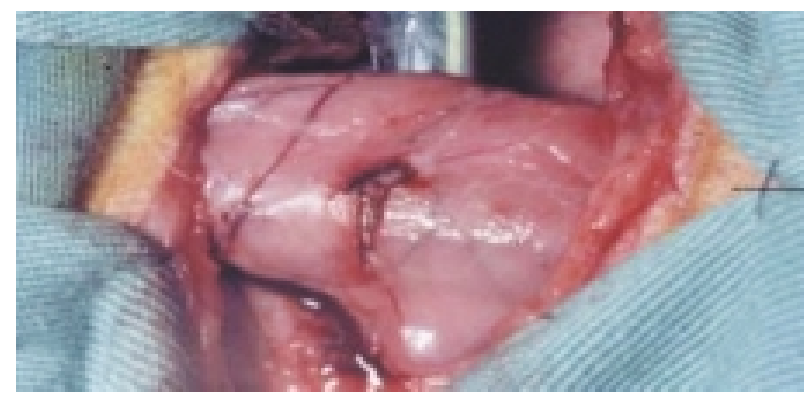

FIGURA 1 - Aspecto da lesão provocada no esôfago.

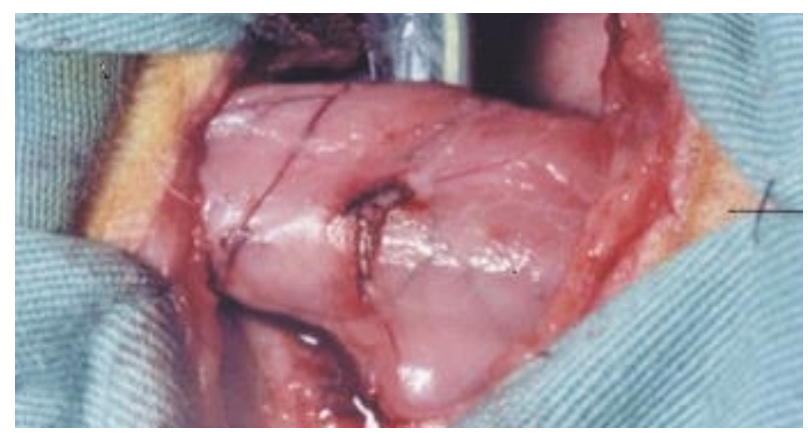

FIGURA 3 - SID aplicada ao esôfago.

Avaliaram-se os resultados após sessenta dias, quando fez-se a eutanásia aos animais. Analisaram-se os aspectos: macroscópico, microscópico (regeneração tecidual, vascularização, incorporação do enxerto, fibrose, inflamação e colágeno) e tensiométrico. Realizou-se a tensiometria no Laboratório de Análises Destrutivas da PUCPR através do equipamento EMIC ${ }^{\circledR}$, onde se avaliou a força máxima de ruptura. Analisouse a força máxima de ruptura da porção superior (esofagoplastia) e da inferior (esôfago normal). $\mathrm{Na}$ análise estatística adotou-se o teste não-paramétrico de Wilcoxon ${ }^{27}$. Um valor de $\mathrm{p}<0,05$ foi considerado estatisticamente significante.

Analisou-se a regeneração epitelial, a vascularização, a fibrose, a inflamação e a incorporação do enxerto em cortes histológicos corados pela HematoxilinaEosina, enquanto que a concentração do colágeno, pelo Sirus-Red. Avaliou-se neste último a presença de

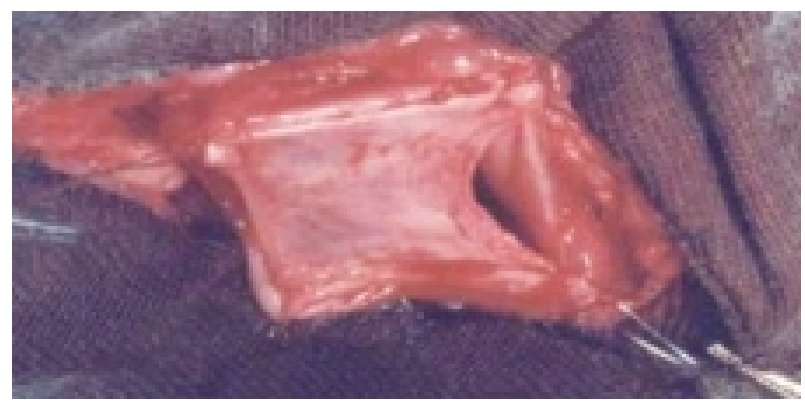

FIGURA 2 - SID sendo fixada à brecha produzida no esôfago.

colágeno tipo I - (fibras mais espessas, fortemente birrefringentes e vermelho-alaranjadas) e colágeno tipo III - (fibras finas e dispersas, pouco birrefringentes e esverdeadas). As imagens foram capturadas numa câmera Sony CCD 101 e transmitidas para um monitor colorido Trinitron Sony. Utilizou-se o aplicativo ImagePro $^{\circledR}$ Plus versão 4.5 para Windows ${ }^{\circledR}$ da Media Cibernetics num computador da linha Pentium. Leuse a porcentagem de colágeno em 3 campos com aumento de 200 vezes, obtendo-se a média de cada corte examinado.

Iniciou-se a alimentação com 24 horas de pósoperatório, com uma dieta pastosa (Sustagemâ). Este alimento foi instituído durante 5 dias, quando então os cães passaram a ser alimentados com a ração tradicional. Não foi administrada antibioticoterapia.

\section{Resultados}

Não houve infecção, fístula ou estenose. Os cães alimentaram-se precocemente. A tensiometria demonstrou ganho de resistência do tecido onde se implantou o enxerto, uma vez que a resistência à ruptura foi semelhante ao controle, com discreta tendência a ser maior. A ruptura ocorreu, em todos os animais, cranialmente ao local de implantação do enxerto. A média da força de ruptura foi de $28,60 \mathrm{~N}$ na metade inferior do esôfago cervical (controle) e de $31.84 \mathrm{~N}$ na metade superior (com enxerto). (Tabelas 1 e 2 ) $(\mathrm{p}=0,593)$.

TABELA 1 - Tensiometria das porções esofagianas de controle (Newtons).

\begin{tabular}{llrl}
\hline \multicolumn{4}{c}{ Força Máxima (N) - Controle } \\
\hline Cão 1 & 15.87 & Cão 6 & 23.67 \\
Cão 2 & 30.69 & Cão 7 & 27.94 \\
Cão 3 & 40.24 & Cão 8 & 29.99 \\
Cão 4 & 22.10 & Cão 9 & 37.02 \\
Cão 5 & 30.21 & Cão 10 & 28.28 \\
\hline \multicolumn{5}{c}{ Média } & $=28,60 \mathrm{~N}$ & \\
& & Desvio Padrão $=6.66$ & \\
\hline
\end{tabular}


TABELA 2 - Tensiometria das porções esofagianas com enxerto SID (Newtons).

\begin{tabular}{lccc}
\hline \multicolumn{4}{c}{ Força Máxima (N) - Com Enxerto SID } \\
\hline Cão 1 & 23.37 & Cão 6 & 31.16 \\
Cão 2 & 42.37 & Cão 7 & 28.45 \\
Cão 3 & 37.24 & Cão 8 & 30.44 \\
Cão 4 & 26.64 & Cão 9 & 41.22 \\
Cão 5 & 32.65 & Cão 10 & 24.87 \\
\hline \multicolumn{5}{c}{} \\
\hline
\end{tabular}

$\mathrm{O}$ aspecto macroscópico demonstrou o local do enxerto já cicatrizado, com cobertura completa da camada mucosa. Externamente não foi possível identificar cicatriz na camada muscular (Figura 4).

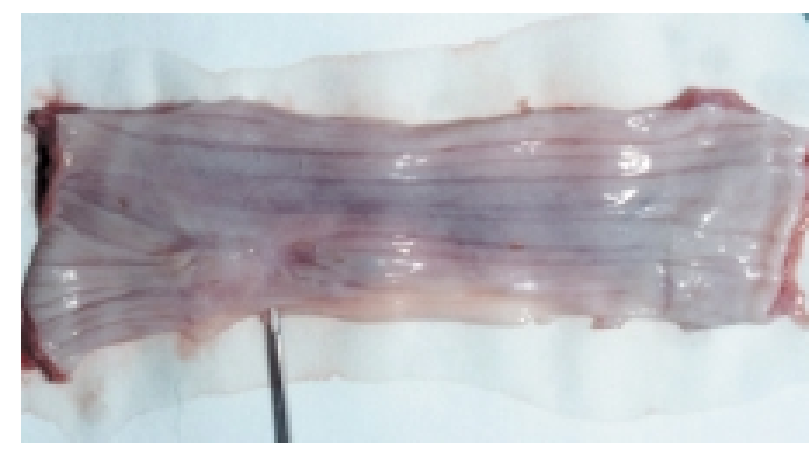

FIGURA 4 - Segmento de esôfago, visto pela sua superfície mucosa, demonstrando a área do enxerto.

O estudo anátomo-patológico pela coloração HE revelou re-epitelização completa e incorporação do enxerto em todos os casos (Figura 5). A proliferação fibroblástica foi intensa em $80 \%$ dos cães e moderada em $20 \%$. Em relação à proliferação neovascular, esta foi moderada em $30 \%$ dos casos e discreta, em $70 \%$. A resposta inflamatória por monomorfonucleares foi ausente na maioria dos cães $(60 \%)$. Em $20 \%$ foi discreta e nos outros 20\%, moderada. Em $30 \%$ dos cães a resposta histológica foi a ideal para todos os parâmetros analisados (re-epitelização completa, incorporação do enxerto, neovascularização, inflamação e proliferação fibroblástica). Nos demais $70 \%$ a resposta foi quase a ideal considerando-se os 5 parâmetros avaliados (Tabelas 3 e 4).

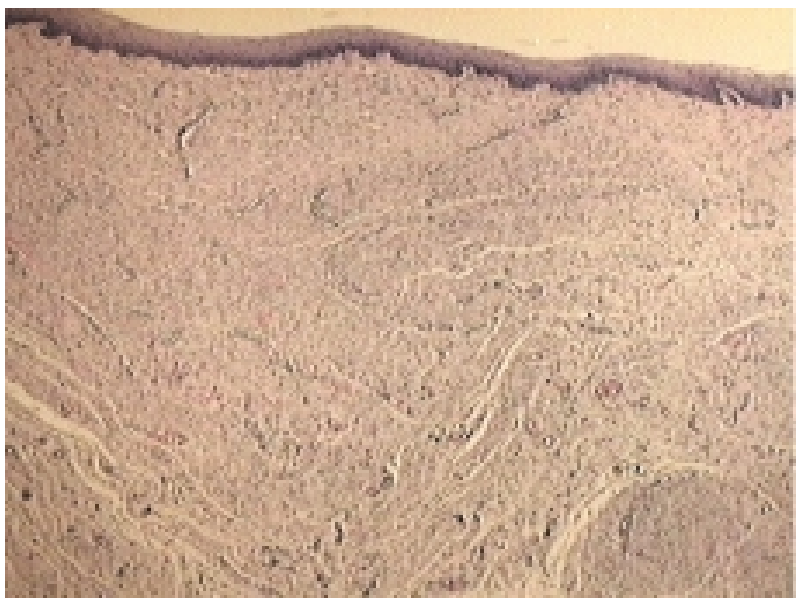

FIGURA 5 - Fotomicrografia de área de enxerto demonstranto mucosa totalmente epitelizada. 
TABELA 3 - Estudo histopatológico (HE). Regeneração completa da mucosa.

\begin{tabular}{ccccc}
\hline animal & fibrose & iimmn & reepitelização & Proliferação Vascular \\
\hline Cão1 & 3 & 1 & 3 & 1 \\
Cão2 & 2 & 2 & 3 & 1 \\
Cão3 & 3 & 2 & 3 & 1 \\
Cão4 & 3 & 0 & 3 & 1 \\
Cão5 & 2 & 1 & 3 & 1 \\
Cão6 & 3 & 0 & 3 & 2 \\
Cão7 & 3 & 0 & 3 & 1 \\
Cão8 & 3 & 0 & 3 & 2 \\
Cão9 & 3 & 0 & 3 & 1 \\
Cão10 & 3 & 0 & 3 & 2 \\
\hline
\end{tabular}

Grau $0=$ ausente $\quad$ Grau $1=$ discreta

Grau 2 = moderada Grau 3 = intensa/completa

iimmn: inflamação induzida por monomorfonucleares

TABELA 4 - Variáveis histopatológicas: percentual dos fatores analisados.

\begin{tabular}{ccccc}
\hline classificação & fibrose & inflamação (iimmn) & reepitelização & Proliferação vascular \\
\hline Ausente & $0(0 \%)$ & $6(60 \%)$ & $0(0 \%)$ & $0(0 \%)$ \\
Discreta & $0(0 \%)$ & $2(20 \%)$ & $0(0 \%)$ & $7(70 \%)$ \\
Moderada & $2(20 \%)$ & $2(20 \%)$ & $0(0 \%)$ & $3(30 \%)$ \\
Intensa & $8(80 \%)$ & $0(0 \%)$ & $10(100 \%)$ & $0(0 \%)$ \\
\hline
\end{tabular}

A quantificação do colágeno pela coloração Sirusred demonstrou haver maior porcentagem de colágeno tipo I. em $90 \%$ dos esôfagos. A concentração de colágeno tipo I entre $18,02 \%$ e $80,89 \%$, com média de
$54,04 \%$. A de colágeno tipo III oscilou entre 7,08\% e $30,09 \%$ (média de $16,04 \%$ ) e a de colágeno total, entre $39,28 \%$ e $93,12 \%$ (média de $71,58 \%$ ) (Tabela 5). Os intervalos de confiança são demonstrados na tabela 6 .

TABELA 5 - Percentagem da área da ferida ocupada por colágeno.

\begin{tabular}{cccc}
\hline Animal & Colágeno Imaturo ( III ) & Colágeno Maduro ( I ) & Colágeno Total \\
\hline Cão 1 & 16, O5 \% & $30.84 \%$ & $46,90 \%$ \\
Cão 2 & $10,47 \%$ & $76,76 \%$ & $87,23 \%$ \\
Cão 3 & $30.09 \%$ & $30.52 \%$ & $60.61 \%$ \\
Cão 4 & $26.91 \%$ & $37.59 \%$ & $79.07 \%$ \\
Cão 5 & $09.32 \%$ & $36.71 \%$ & $45.93 \%$ \\
Cão 6 & $21.53 \%$ & $18.02 \%$ & $39.28 \%$ \\
Cão 7 & $07.08 \%$ & $80.89 \%$ & $88.69 \%$ \\
Cão 8 & $12.35 \%$ & $80.77 \%$ & $93.12 \%$ \\
Cão 9 & $15.18 \%$ & $74.71 \%$ & $89.89 \%$ \\
Cão 10 & $11.47 \%$ & $73.66 \%$ & $85.13 \%$ \\
\hline MÉDIA & $16.04 \%$ & $54.04 \%$ & $71.58 \%$ \\
\hline
\end{tabular}


TABELA 6 - Intervalos de 95\% de confiança para os percentuais médios de colágeno.

\begin{tabular}{cccccc}
\hline Variável & Média & $\begin{array}{c}\text { Valor } \\
\text { Mínimo }\end{array}$ & $\begin{array}{c}\text { Valor } \\
\text { Máximo }\end{array}$ & $\begin{array}{c}\text { Desvio } \\
\text { Padrão }\end{array}$ & $\begin{array}{c}\text { Intervalo de 95\% } \\
\text { de Confiança }\end{array}$ \\
\hline Colágeno III (\%) & 16,05 & 7,08 & 30,09 & 7,727 & $(10,52 ;$ \\
Colágeno I (\%) & 54,05 & 18,02 & 80,89 & 25,218 & $(36,01 ;$ \\
& & & & & $72,09)$ \\
Colágeno total (\%) & 71,59 & 39,28 & 93,12 & 21,101 & $(56,49 ;$ \\
& & & & & $86,68)$ \\
\hline
\end{tabular}

\section{Discussão}

Grandes lesões esofágicas com significativa perda tecidual são preocupantes e de difícil tratamento ${ }^{3,11}$. Requerem técnicas inovadoras e apresentam elevada morbidade. Em se tratando de vítimas de feridas traumáticas, as quais normalmente apresentam lesões associadas como dos grandes vasos do pescoço, traquéia e coluna cervical, as chances de sobrevida e qualidade de vida são melhores quando o reparo da lesão é realizado de maneira concreta e definitiva e num menor espaço de tempo. O reparo primário é viável somente em lesões pequenas e recentes, pois, do contrário, as técnicas de exclusão e estomização poderão predispor à posteriores procedimentos de reconstrução, mais extensos, como as interposições gástrica e colôni$\mathrm{ca}^{3,5,6,9,10}$. Mesmo com o avanço da terapia intensiva e dos antibióticos, que diminuíram os índices de mortalidade, os custos e a morbidade continuam altos.

Bons resultados foram obtidos recentemente com diferentes tipos de enxerto para reparo de lacerações esofágicas, como o uso da própria submucosa de intestino delgado ${ }^{26}$, o uso de pele humana descelularizada ${ }^{28}$ e de aorta porcina descelularizada ${ }^{4}$.

O enxerto que empregamos no reparo de lesões esofágicas cervicais pode ser obtido fácil e rapidamente, com baixo custo. A SID proporciona uma barreira no sítio da lesão enquanto, rapidamente pela matriz colágena, o tecido local cresce e se regenera, tomando seu lugar ${ }^{19-21}$.

A tensiometria das peças esofágicas demonstrou que aos 60 dias a força necessária para ruptura é semelhante nas áreas com enxerto, à das áreas controle. Isso significa que a resistência do material se apresenta adequada a curto-médio prazo. Badylak (2000) relatou ser o local do enxerto discretamente mais resistente do que o esôfago normal num estudo semelhante $^{26}$.
A histologia evidenciou proliferação fibroblástica intensa em $80 \%$ dos $\operatorname{casos}^{19}$. Isso representa que ocorreu excelente cicatrização do local do enxerto, confirmando o resultado do estudo tensiométrico. Houve re-epitelização completa da mucosa em $100 \%$ dos $\operatorname{casos}^{26}$, no entanto, não foi possível avaliar com precisão a regeneração da camada muscular ${ }^{4,21,26}$; para isto será necessária contagem de células através de imunohistoquímica. Segundo Badylak (2000), há uma organização relativa da camada muscular quando a SID é implantada no esôfago. Quanto a neovascularização, esta foi de discreta a moderada $3,7,12,26$. Isto foi considerado bom para um órgão que certamente apresentou desvascularização importante ao ser manuseado e é, naturalmente, pouco angiogênico. A incorporação do enxerto foi completa em $100 \%$ dos casos e a resposta inflamatória, aos 60 dias, foi nula na maioria dos animais ${ }^{2,4,19,20,22}$.

Os resultados verificados na coloração Sirus-red vieram a confirmar a satisfatória resposta cicatricial apresentada pelo enxerto. Com 60 dias de pósoperatório, a porcentagem de colágeno tipo III foi de $54,04 \%$ e de colágeno total de $71,58 \%$, valores considerados suficientes para uma boa cicatrização. Certamente este colágeno conferiu a boa resposta tensiomátrica ao enxerto.

Baseados na experiência de Badylak (2000), não nos dispusemos a substituir uma eventual perda pela ressecção da totalidade da circunferência do esôfago. Segundo o autor, quando executado este procedimento, há elevada morbidade e mortalidade associadas ao elevado grau de estenose instalado ${ }^{26}$.

Com características de não haver rejeição ou infecção e de neovascularização ${ }^{12,18-26}$, a matriz colágena extracelular se encaixa como uma base propícia para uma regeneração tecidual, com baixíssimo grau de retração tecidual, sem estenose significante e sem o aparecimento de fístulas. 


\section{Conclusão}

A submucosa de intestino delgado porcina é um enxerto eficaz no reparo de lesões com perda de substância do esôfago cervical em cães.

\section{Referências}

1. Gardner E, Gray D, O'Rahhily. Anatomia. 4ed. Rio de Janeiro: Guanabara- Koogan; 1988.

2. Di Fiore M, Mancini R, De Robertis E. Novo atlas de histologia. 2ed. Rio de Janeiro: Guanabara-Koogan; 1973.

3. Banecko RM, Shields TW. Esofageal trauma. Gen Thor Surg 1994;24:1514-25.

4. Kajitani M, Wadia Y, Hinds M, Teach J, Swartz K, Gregory K. Successful repair of esophageal injury using a elastin based biomaterial patch. Asaio J 2001; 46:342-5.

5. Grillo HG, Wilkins EW. Esophageal repair following late diagnosis of intrathoracic perforation. Ann Thorac Surg 1975; 29:387-99.

6. Thal AP, Hatafuku T, Kurtzman R. New operation for distal esophageal stricture. Arch Surg 1965; 90:464-72.

7. Urschel Jr HC, Razzuk MA, Wood RE. Improved management of esophageal perforations. Thorax 1977; 32:241-9.

8. Pass LJ, LeNarz LA, Schreiber JT. Management of esophageal gunshot wounds. Ann Thorac Surg. 1987; 44:253-6.

9. Popovski J. Perforation of the esophagus for gunshot wuonds. J Trauma 1984; 24:337-9.

10. DeMeester TR: Perforation of the esophagus (editorial). Ann Thorac Surg. 1986.

11. Demetríades D, Asensio J, Velmahos G. Problemas complexos no traumatismo cervical penetrante. In: Asensio J, Demetriades D, Berne T. Clinicas irúrgicas da América do Norte: problemas complexos e desafiadores na cirurgia traumatológica. Rio de Janeiro: Interlivros Edições; 1996. p 681-2.

12. Roeder R, Wolf J, Lianakis N. Compliance, elastic modulus, and burst pressure of small-intestine submucosa (SIS), smalldiameter vascular grafts. J Biomed Mater Res 1999;47: 65.

13. Vaught JD, Kropp BP, Sawyer BD, Rippy MK, Badylak SF, Shannon HE, Thor, KB. Detrusor regeneration in the rat using porcine small intestine submucosal grafts: functional inervation e receptor expression. J Urol 1996; 155:374-8.

14. Badylak SF, Kropp B, McPherson T. Small intestinal submucosa: a rapidly resorbed bioscaffold for argumentation cytoplasty in a dog model. Tissue Eng 1998; 4:379.

15. Prevel C, Eppley B, Summerlin DJ, Jackson JR, McCarty M, Badylak SF. Small intestinal submucosa: utilization for repair of rodent abdominal wall defects. Ann Plast Surg 1995; 34:374-80.

16. Peel SAF, Chen H, Renlund R, Badylak SF, Kandel RA. Formation of a SIS-cartilage composite graft in vitro and its use in the repair of articular cartilage defects. Tissue Eng 1998; 4:143-55.

17. Hodde JP, Badylak SF, Brightman AO, Voyti-Harbin SL. Glycosaminoglycan content of small intestine submucosa: a bioscaffold for tissue replacement. Tissue Eng 1996; 2:209-17.

18. Hodde JP, McPherson TB, Savaiano JK, Badylak SF. Vascular endotelial growth factor (VEGF) in SIS. SIS Symp1998; p92.

19. Liang, HA. Determination of platelet-derivad growth factor in small intestinal submucosa. SIS Simp 1998; p93.

20. Voytik-Harbin SL, Brightman AO, Kraine M, Waisner B, Badylak, SL. Identification of extractable growth factors from small intestinal submucosa. J Cel Bio 1997; 67:478-91.

21. McPherson TB, Badylak SF. Characterization of fibronectin derived from porcine small intestinal submucosa. Tissue Eng 1998; 4:75-83.

22. McPherson TB, Badylak SF, Hogenesch, H., et al. Efect of local response to xenogeneic ECM on systemic immunity. SIS Symp 1998; p34.

23. Metzger DW, McPhersonTB, Merrill LA, Moyad TF, Badylak SF. Immune responses to xenogeneic SIS Implants. SIS Symp 1998; p33.

24. Allman AJ, McPherson TB, Timothy B, Badylak SF, Merril LC, Kallakury B, Sherran C, Raeder RH, Metzger DW. Xenogeneic extracellular matrix grafts elicit a th-2-restricted immune response. Transplantation 2001;71: 1631-40.

25. Badylak SF, Coffei AC, Lantz GC. Comparison of resistance to infection of small intestinal submucosa arterial autografts versus polytetrafluoroethilene arterial prostheses in a dog model. J Vasc Surg 1994;19:465.

26. Badylak SF, Meurlin S, Chen M. Resorbable bioscaffold for esophageal repair in a dog model. J Pediatr Surg 2000; 35:1097-103.

27. Siegel S. Nonparametric statistics. New York: McGraw-Hill Book Company; 1956.

28. Isch JA, Eugum SA, Ruble CA. Patch esophagoplasty using AlloDerm as a tissue scaffold. J Pediatr Surg 2001;36:266-8.

\section{Agradecimentos}

Prof ${ }^{\text {a }}$ Márcia Holanoski (Estatística), Álvaro e Daniel (Técnica Operatória), Indalécio Sutil (Veterinário), Rosana Nunes (Técnica Operatória), Fernando Ubirajara (Biotério). 
Souza Filho ZA, Ioshii SO, Greca FH, Biondo-Simões MLP, Rocha SL, Duda JR, Oliveira Filho HR. Small intestine submucosa for repair of cervical esophageal lesions in a dog model. Acta Cir Bras [serial online] 2003 May-Jun;18(3). Available from URL: http://www.scielo.br/acb.

ABSTRACT - Purpose: Study of porcine small intestinal submucosa (SIS) efficiency as a graft in the handling of lesions of the cervical esophagus in dogs. Methods: Ten dogs were operated. A resection of a portion of the anterior wall of the esophagus was performed, followed by its repair with a SIS graft. The tensiometric resistance, macroscopic appearance regeneration process and collagen contents of the esophagus tissue were evaluated. Results: No cases of fistula, stenosis or infection occured. Tensiometric evaluation showed a similar resistance in the operated esophagus when compared to the control (an average of $31.84 \mathrm{~N}$ against $28.60 \mathrm{~N}$ ). Macroscopic analysis revealed complete healing with little tissue retraction. Pathology HE study showed complete mucous membrane regeneration, discrete to moderate vascular proliferation and intense fibroblastic proliferation. Collagen analysis by Sirus-red staining found $54.04 \%$ of mature collagen, $16,04 \%$ of imature collagen as well as $71.58 \%$ of total collagen. Conclusion: SIS has proved to be an efficient graft when used in the repairing of canine large esophagus lesions, featuring infection and rejection resistance. Complete regeneration was observed in $100 \%$ of the cases. SIS should, therefore, be considered as an important option in treatment of esophageal injuries.

KEY WORDS - Injuries. Esophagus. Submucosa. Experimental surgery.

Conflito de interesse: nenhum

Correspondência:

Fonte de financiamento: PIBIC-PUCPR

Zacarias Alves de Souza Filho

R. Padre Agostinho, 1923/1901

80710-000 Curitiba - PR

Tel: (41)336-3445

joaorduda@ hotmail.com.br

Data do recebimento: 21/02/2003

Data da revisão: 10/03/2003

Data da aprovação: 24/03/2003 